\title{
AS CONTRIBUIÇÕES DAS PRODUÇÕES CIENTÍFICAS NA TEMÁTICA "ENFERMAGEM E MEIO AMBIENTE": UMA REVISÃO NARRATIVA
}

\author{
THE CONTRIBUTIONS OF SCIENTIFIC PRODUCTIONS IN THE AREA OF NURSING \\ AND ENVIRONMENT: A NARRATIVE REVIEW
}

\section{Roger Rodrigues Peres ${ }^{\mathrm{a}^{*}}$, Silviamar Camponogara ${ }^{\mathrm{b}^{*}}$, Sabrina Gonçalves Aguiar Soares ${ }^{\mathrm{c}^{*}}$,Paola da Silva Diaz ${ }^{\mathrm{d}^{*}}$}

aroger_rrp@yahoo.com.br, bsilviaufsm@yahoo.com.br, cenfsabrinasoares@yahoo.com.br, dpaolinha_diaz@hotmail.com * Universidade Federal de Santa Maria - Santa Maria (RS), Brasil

\section{RESUMO}

Introduçáo: A sociedade vivencia uma crise ambiental que afeta diretamente a vida humana, exigindo, assim, que a enfermagem desperte para a relação existente entre saúde e meio ambiente, para enfrentar as novas demandas desse cenário ambientalmente conturbado. Objetivo: Descrever as contribuiçóes das produçôes científicas sobre a temática "enfermagem e meio ambiente". Materiais e métodos: Estudo qualitativo, descritivo, caracterizado como revisão narrativa da literatura. As bases de dados pesquisadas foram o Banco de Dados de Enfermagem (BDENF), a Literatura Latino-Americana e do Caribe em Ciências da Saúde (LILACS) e a Medical Literature Analysis and Retrieval System On-line.(Medline). Foram utilizados os descritores "enfermagem", "educação ambiental”, "meio ambiente", "ecologia", "saúde ambiental" e "desenvolvimento sustentável". A pesquisa foi realizada no mês de agosto de 2013 e não teve recorte temporal. Resultados: Os artigos que compóem o corpus de análise evidenciam concepçôes frágeis sobre meio ambiente e saúde ambiental. Demonstram, também, preocupação com a falta de conhecimento dos profissionais da saúde sobre resíduos dos serviços de saúde e seu gerenciamento, além de dificuldades do trabalho multiprofissional com relação ao tema. Diferentes investigaçóes apontam a necessidade de uma abordagem mais efetiva na formação profissional sobre questóes ambientais em busca de uma consciência ética e ambientalmente responsável. Conclusóes: Faz-se necessário a realização de novas pesquisas que fortifiquem o conhecimento da enfermagem na temática socioambiental, explorando novas concepçóes e práticas presentes no trabalho do enfermeiro, tendo em vista a importância do tema para a formação de profissionais ambientalmente responsáveis e, consequentemente, uma realidade mais saudável.

Palavras-chave: Enfermagem; meio ambiente; saúde ambiental.

\section{ABSTRACT}

Introduction: Society is under an environmental crisis that affects directly human life and therefore demands the nursing area to comprehend the relationship that exists between health and environment to be able to face the new demands that are present in this environmentally disturbed scenery. Aim: To describe the contributions of scientific productions about the nursing area concerning the environment. Method: This is a qualitative and descriptive study, characterized as a narrative literature review. The researched databases were the Nursing Database, the Latin-American and Caribbean Literature on Health Sciences and the Medical Literature Analysis and Retrieval System Online through the use of the following descriptors: "nursing", "environmental education", "environment", "ecology”, "environmental health", and "sustainable development". The research was carried out in August of 2013 with no demarcation. Results: The articles that compose the corpus show fragile conceptions about the environment and environmental health. They also show concern about the health professionals' lack of knowledge about the residues of 
health services and their management, plus the difficulties of multi-professional work about the topic. In terms of professional formation, different investigations point to the need of a more effective approach about the environmental issues to achieve ethical and environmentally responsible awareness. Conclusions: New researches must be done to consolidate the nursing knowledge on the socio-environmental area and also to exploring new conceptions and practices that are present in the nurse's work, considering the importance of the topic to the formation of environmentally responsible professionals and, consequently, a healthier reality.

Keywords: Nursing; environment; environmental health.

\section{Introdução}

A humanidade tem buscado o domínio sobre o ambiente desde seus primórdios, em prol de sua segurança e conforto, esquecendo-se, por vezes, que pertence e depende do equilíbrio dos ecossistemas. A busca sem limites pelo crescimento econômico e o alto consumo dos recursos naturais são reflexos desse esquecimento que acabam influenciando também outros aspectos da vida social, como saúde, cultura, política, respeito, solidariedade, entre outros. Esse panorama, mais evidente a partir dos anos 60, reforça a certeza de que a sociedade contemporânea vivencia uma crise complexa e multidimensional, exigindo mudanças na forma de pensar a relação homem-ambiente ${ }^{1}$.

O comportamento antropocêntrico, fragmentador e consumista de mundo se apresenta como um grave problema a ser resolvido pela comunidade global, devido, principalmente, a sua fórmula promissora que prevaleceu na modernidade, mas que tem gerado frutos como a marginalizaçáo social, o empobrecimento cultural e a precariedade da saúde. Emerge dessa situação a necessidade de um novo paradigma, que pode ser chamado de visão holística ou ambiental do mundo, em que reconhece a interdependência fundamental de todos os fenômenos através da perspectiva socioambiental ${ }^{1}$.

A área da saúde vivencia essa crise de maneira muito próxima, tendo que trabalhar com uma sociedade afetada por diferentes problemas ambientais, como epidemias, enchentes, mudanças climáticas, nutrição inadequada, entre outros. Ao mesmo tempo, também se observa o ser humano causando situaçóes de prejuízo ecológico, como o descarte inadequado de materiais, alto consumo de produtos, desmatamento, poluição etc. Essa intimidade com as diferentes circunstâncias deveria despertar o alerta para uma sensibilização do setor de saúde com a causa. Entretanto, o que se observa é que a ótica de saúde associada ao meio ambiente ainda está pouco incorporada nos profissionais, revelando um processo tímido de responsabilização/ação ${ }^{2}$.

Dessa forma, torna-se necessário que a área da saúde desperte para a relação entre saúde e meio ambiente, considerando que as consequências do desequilíbrio ecológico afetam diretamente a vida humana ${ }^{3,4}$.
Nesse ínterim encontra-se a enfermagem, profissão que tem o cuidado na sua essência. $O$ próprio surgimento da prática de enfermagem confirma seu envolvimento secular com as questóes ambientais por meio de sua precursora Florence Nightingale, que já apontava que o ambiente tem papel fundamental no cuidado à saúde. Entretanto, as mudanças na prática de enfermagem após o fim da II Guerra Mundial e uma confluência de outros fatores levaram-na, gradualmente, a um afastamento da ênfase na saúde ambiental'5.

Nessa perspectiva, percebe-se que tem havido um tímido ressurgimento do interesse da enfermagem para com as questóes ambientais através da avaliação de exposição a toxinas, educação na comunidade e preocupação com os Resíduos dos Serviços de Saúde (RSS), motivado por algumas políticas governamentais relacionadas ao tema. Apesar disso, ainda se observa que poucos estudos abordam a temática ambiental com reflexôes mais amplas, que extrapolam a relação causa-efeito do ambiente na saúde das pessoas, contribuindo para a construção de uma nova perspectiva ambiental na enfermagem e na saúde $e^{4,5,6}$.

Neste cenário, faz-se necessário conhecer o que tem sido produzido na atualidade sobre a relação entre enfermagem e meio ambiente. Cabe destacar, nesse caso, que o enfermeiro tem o importante papel, náo só na prestação de cuidados diretos à população, mas também na conformação do sistema de saúde, no processo de educação em saúde da população e, ainda, para a formação das novas geraçóes de profissionais, sendo que em todos esses aspectos o meio ambiente está atrelado como dimensão fundamental para a promoção de saúde e qualidade de vida.

Dessa maneira, a questão de pesquisa que guiou este estudo foi: Quais as contribuições das produções científicas sobre a temática enfermagem e meio ambiente? $\mathrm{Na}$ intenção de responder essa questão, objetivou-se descrever tais contribuiçóes.

\section{Método}

O presente artigo é uma revisão narrativa da literatura. Tal pesquisa caracteriza-se por ser ampla, geralmente partindo de uma temática mais aberta, demonstrando-se 
apropriada para descrever e discutir o desenvolvimento ou o "estado da arte" de um determinado assunto, tendo também papel fundamental para a educação continuada, pois permite ao leitor adquirir e atualizar o conhecimento sobre uma temática específica em curto espaço de tempo ${ }^{7,8}$.

A realização desta revisão obedeceu às seguintes etapas: identificação do tema, construçâo da questão norteadora, definiçâo dos critérios de seleção da amostra, escolha das informações para extração nos artigos selecionados, pesquisa e teste dos descritores mais adequados para obtenção dos dados, realização da pesquisa e refinamento da amostra, avaliação dos artigos seguida de categorização e interpretação e apresentaçấo dos resultados.

A busca das produçóes científicas foi realizada nas bases de dados Banco de Dados de Enfermagem (BDENF), Literatura Latino-Americana e do Caribe em Ciências da Saúde (LILACS) e na Medical Literature Analysis and Retrieval Sistem On-line (Medline). O levantamento dos dados ocorreu no mês de agosto de 2013, por meio da seguinte associação de descritores e idiomas, em formulário avançado, nas diferentes bases de dados: "enfermagem" [Descritor de assunto] and ( "educação ambiental") or "MEIO AMBIENTE") or "ECOLOGIA" ) or "saude ambiental") or "desenvolvimento sustentavel" [Descritor de assunto] and "ESPANHOL" or "INGLES" or "PORTUGUES" [Idioma].

Para seleção da amostra, não houve recorte temporal, pois o estudo tentou capturar todas as produçóes publicadas até o ano de 2012. Como critérios de inclusão foram utilizados: ser artigo científico, estar disponível on-line na íntegra gratuitamente e versar sobre a temática pesquisada.

A pesquisa na base de dados BDENF resultou em 16 artigos, sendo três excluídostrês por estarem repetidos na própria base de dados e outros três por não estarem disponíveis on-line na íntegra, restando dez artigos. $\mathrm{Na}$ base de dados da LILACS foram encontrados 14 documentos, sendo nove excluídosnove por já terem sido encontrados na BDENF, dois por não serem artigos, um por não ter relação com a temática e um estudo por não estar disponível online na íntegra, restando um artigo. No Medline, a busca resultou em 109 documentos, sendo excluídos três por serem repetidos, seis por não serem artigos, 47 por não terem relação com a temática e outros cinquenta por não estarem disponíveis on-line na íntegra gratuitamente, restando três artigos para análise. Dessa forma, restaram 14 produçóes científicas do montante de 139 achados para compor o corpus de análise do estudo.

No intuito de facilitar a compreensão dos achados da literatura científica presentes nos resultados e sua discussão, elaborou-se um quadro contendo as referências dos artigos, conforme disposto na Tabela 1 .
Tabela 1: Corpus da pesquisa de revisão narrativa da literatura na temática enfermagem e meio ambiente

\begin{tabular}{|c|c|}
\hline $\mathbf{n}$ & Referências dos estudos analisados \\
\hline $\mathrm{A} 1$ & $\begin{array}{l}\text { Silva ITS, Bonfada D. Resíduos sólidos de serviços } \\
\text { de saúde e meio ambiente: percepçáo da equipe de } \\
\text { enfermagem. Rev Rene. 2012;13(3):650-7. }\end{array}$ \\
\hline A2 & $\begin{array}{l}\text { Soares SGA, Camponogara S, Terra MG, Santos } \\
\text { TM, Trevisan CM. O que pensam os enfermei- } \\
\text { ros sobre a problemática ambiental. Rev Rene. } \\
\text { 2012;13(5):971-82. }\end{array}$ \\
\hline A3 & $\begin{array}{l}\text { Camponogara S, Soares SGA, Terra MG, Santos TM, } \\
\text { Trevisan CM. Nurses involved in management of hos- } \\
\text { pital residues: a descriptive study. Online Braz J Nurs. } \\
2012 \text { aug; } 11(2): 289-304 \text {. }\end{array}$ \\
\hline A4 & $\begin{array}{l}\text { Camponogara S, Erthal G, Viero CM, Diaz PS, } \\
\text { Soares SGA, Peres RR. The perception of students of } \\
\text { the area of health about the environmental pro- } \\
\text { blems: a descriptive study. Online Braz J Nurs. } 2012 \\
\text { aug;11(2):376-91. }\end{array}$ \\
\hline A5 & $\begin{array}{l}\text { Lopes MSV, Ximenes LB. Enfermagem e saúde am- } \\
\text { biental: possibilidades de atuação para a promoçáo da } \\
\text { saúde. Rev Bras Enferm. } 2011 \text { jan-fev;64(1):72-7. }\end{array}$ \\
\hline A6 & $\begin{array}{l}\text { Beserra EP, Alves MDS, Pinheiro PNC, Vieira } \\
\text { NFC. Educação ambiental e enfermagem: uma } \\
\text { integraçáo necessária. Rev Bras Enferm. } 2010 \\
\text { set-out;63(5):848-52. }\end{array}$ \\
\hline A7 & $\begin{array}{l}\text { Baggio MA, Callegaro GD, Erdmann AL. } \\
\text { Significando o cuidado ecológico/planetário/coletivo/ } \\
\text { do ambiente à luz do pensamento complexo. remE - } \\
\text { Rev Min Enferm. } 2011 \text { jan-mar;15(1):11-18. }\end{array}$ \\
\hline A8 & $\begin{array}{l}\text { Beserra EP, Alves MDS, Rigotto MR. Percepção de } \\
\text { adolescentes acerca da saúde ambiental: pesquisa-ação } \\
\text { no espaço escolar. Online Braz J Nurs. 2010;9(1). }\end{array}$ \\
\hline A9 & $\begin{array}{l}\text { Camponogara S, Kirchhof ALC, Ramos FRG. A rela- } \\
\text { ção enfermagem e ecologia: abordagens e perspectivas. } \\
\text { R Enferm UERJ. } 2006 \text { jul-set;14(3):398-404. }\end{array}$ \\
\hline A10 & $\begin{array}{l}\text { Monteiro EMLM, Rolim KMC, Machado MFAS, } \\
\text { Moreira RVO. A visão ecológica: uma teia na enferma- } \\
\text { gem. Rev Bras Enferm. } 2005 \text { maio-jun;58(3):341-4. }\end{array}$ \\
\hline A11 & $\begin{array}{l}\text { Beserra EP, Alves MDS. Enfermagem e saúde ambien- } \\
\text { tal na escola. Acta Paul Enferm. 2012;25(5):666-72. }\end{array}$ \\
\hline A12 & $\begin{array}{l}\text { Cezar-Vaz MR, Muccillo-Baisch AL, Soares JFS, Weis } \\
\text { AH, Costa VZ, Soares MCF. Concepções de enfer- } \\
\text { magem, saúde e ambiente: abordagem ecossistêmica } \\
\text { da produção coletiva de saúde na atenção básica. Rev } \\
\text { Latino-Am Enferm. } 2007 \text { mai-jun;15(3). }\end{array}$ \\
\hline A13 & $\begin{array}{l}\text { Ribeiro MCS, Bertolozzi MR. A questão ambiental } \\
\text { como objeto de atuação da vigilância sanitária: uma } \\
\text { análise da inserção das enfermeiras nesse campo. Rev } \\
\text { Latino-Am Enferm. } 2004 \text { set-out;12(5):736-44. }\end{array}$ \\
\hline A14 & $\begin{array}{l}\text { J Wakefield. Environmental Florence Nightingales: } \\
\text { nursing's new front line. Environ Health Perspect. } \\
2001 \text { mar;109(3):A118-A123. }\end{array}$ \\
\hline
\end{tabular}

De posse dos artigos selecionados, procedeu-se com a leitura criteriosa, organizando os artigos em três quadros analíticos confeccionados pelos autores. $\mathrm{O}$ primeiro foi feito com o intuito de extrair dados como código da base de dados, autores, categoria profissional, titulação e instituição dos autores, periódico, região de 
procedência da produção, título e ano da publicação. $\mathrm{O}$ segundo quadro conteve dados como abordagem do estudo, tipo de estudo, objetivo, sujeitos, técnica de coleta de dados e local da coleta de dados. Por último, utilizou-se um quadro que foi preenchido com os principais resultados e conclusóes dos estudos. Após os dados serem preenchidos nas diferentes tabelas, realizou-se a categorização e análise temática das produçôes ${ }^{9}$, extraindo os dados mais relevantes sobre o tema.

\section{Resultados e discussão}

Os 14 estudos selecionados têm autoria de 33 enfermeiros e outras três categorias profissionais com um autor de cada, respectivamente medicina, fisioterapia e filosofia. Este dado é previsível, considerando o tema da pesquisa, enfermagem e meio ambiente, mas corrobora com o importante cenário atual de pesquisa em enfermagem, no qual os enfermeiros vêm ocupando espaço de destaque na produção científica brasileira e mundial, reafirmando e qualificando a produção de conhecimento em saúde e enfermagem ${ }^{10}$ e explorando temáticas até então pouco investigadas, como a ambiental.

Quanto à titulação dos autores $(\mathrm{n}=36)$ no momento da publicação do estudo, observa-se que 66\% ( $n=24)$ são doutores ou doutorandos, $22 \%(\mathrm{n}=08)$ são mestres ou mestrandos e o restante, que compreende $12 \%$ $(\mathrm{n}=04)$, contém graduação ou especialização. Esse panorama da produção pode ser interpretado como possível reflexo da política governamental atual de expansão dos cursos de pós-graduação stricto sensu no Brasil, inclusive na área de enfermagem, na qual, no período de 2007 a 2010, houve aumento de 62\% no número de cursos de mestrado acadêmico e profissional e de $80 \%$ no número de programas de doutorado ${ }^{10}$. Destaca-se ainda que a Universidade Federal do Ceará é a instituição com o maior número de autores entre os estudos selecionados $(\mathrm{n}=11)$, seguida pela Universidade Federal de Santa Maria $(n=9)$, Universidade Federal de Rio Grande (n=6) e Universidade Federal de Santa Catarina $(n=5)$, sendo que outras instituiçóes figuraram com dois ou menos autores.

As regióes Sul e Nordeste do Brasil destacaram-se por serem as de origem de seis estudos cada, restando ainda um estudo oriundo da regiáo Sudoeste e o outro dos Estados Unidos da América. Pode-se explicar parcialmente este fato devido às características dos programas de pós-graduação em enfermagem com pesquisas voltadas para demandas socioambientais presentes nas regióes que compreenderam maior número de estudos, assim como pela predominância de cursos de pósgraduaçáo stricto sensu nas regióes destacadas, estando 20,2\% dos cursos alocados na região Nordeste do Brasil e $19,1 \%$ na região Sul, embora a regiāo Sudeste compreenda 49,4\% dos cursos do Brasil ${ }^{10}$.

No que diz respeito aos periódicos, faz-se o destaque para Revista da Rede de Enfermagem do Nordeste, Online Brazilian Journal of Nursing e Revista Brasileira de Enfermagem com três artigos cada, seguidas pela Revista Latino-Americana de Enfermagem com dois e das demais revistas com uma publicação cada, a saber: ACTA Paulista de Enfermagem, Revista de Enfermagem da Universidade do Estado do Rio de Janeiro e Environmental Health Perspectives. $\mathrm{O}$ ano que compreendeu maior número de achados foi 2012 $(\mathrm{n}=5)$, estando o restante das publicações distribuídas entre os anos de 2001 a 2011.

Dos artigos que formam o corpus de análise $(n=14)$, 11 são pesquisas, sendo dez qualitativas e uma quantitativa, e os outros três artigos restantes são caracterizados como reflexivos. A prevalência de pesquisas qualitativas neste estudo vai ao encontro do cenário científico da área da saúde nas últimas décadas, em que o interesse e realização de estudos com essa abordagem têm aumentado significativamente ${ }^{11}$. Acrescenta-se ainda que essas onze pesquisas caracterizam-se da seguinte maneira: descritivas e exploratórias $(n=6)$, descritivas $(n=2)$, exploratória $(n=1)$, bibliográfica $(n=1)$ e interpretativa $(\mathrm{n}=1)$, segundo descrito no método dos estudos.

Quanto aos sujeitos das pesquisas de campo $(n=10)$, há o predomínio da participação de enfermeiros assistencialistas $(n=4)$ seguidos pela equipe de enfermagem $(n=2)$, estudantes do ensino fundamental $(n=2)$, um estudante da área da saúde $(n=1)$ e um integrante de um comitê de bacia hidrográfica $(n=1)$. $O$ campo de coleta de dados mais utilizado foi o hospital $(n=4)$, estando os demais distribuídos entre atenção básica à saúde $(\mathrm{n}=2)$, instituição de ensino superior $(n=1)$, escola de ensino fundamental $(n=1)$, vigilância sanitária $(n=1)$ e comitê de bacia hidrográfica $(n=1)$. Destaca-se também que a técnica de coleta de dados mais utilizada foi a entrevista semiestruturada $(n=7)$, posteriormente dinâmica grupal $(n=2)$ e pesquisa-ação $(n=1)$.

A análise dos resultados e conclusões das produçóes evidencia três eixos temáticos que dão origem às categorias de discussão deste estudo. São elas: concepção de ambiente e saúde ambiental; resíduos dos serviços de saúde e seu gerenciamento; e formação profissional em enfermagem: ampliando possibilidades.

\section{Concepção de ambiente e saúde ambiental}

Do total de estudos $(n=14), 64 \%(n=9)$ tiveram a intenção de também conhecer a percepção dos sujeitos pesquisados sobre ambiente e a sua relação com a saúde, fornecendo, assim, subsídios para posteriores 
interpretaçóes das questóes centrais dos respectivos estudos. Dessa maneira, alguns achados demonstram-se semelhantes nas diferentes pesquisas, como, por exemplo, a limitação da percepção de ambiente de alguns sujeitos quando o vinculam à natureza unicamente biológica, ou seja, uma percepção naturalística (A2, A4, A13).

Nesse contexto, as pesquisas também apontam que alguns enfermeiros detêm o imaginário de que o ambiente seria o que está "fora" do local de trabalho, o que se revela preocupante na medida em que esses profissionais não atentam para as demandas ambientais que envolvem seu cotidiano laboral, tornando-se difícil o envolvimento com açóes ambientalmente responsáveis. Soma-se a isso outro dado de pesquisa que aponta o fato de que alguns participantes entendem o ambiente enquanto bem de uso em favor dos seres humanos, divergindo da ideia de que há uma interdependência entre todos os seres, sem que haja superioridade de um sobre o outro (A2, A4). Dessa forma, essas percepçóes acabam se distanciando do desejado pensamento ambientalmente consciente, tão necessário frente ao atual cenário de crise ambiental pelo qual a humanidade perpassa.

A percepção de meio ambiente não pode restringirse a uma razão universal, ou seja, a uma caracterização única e fechada, haja vista que não existe um consenso sobre o que é meio ambiente na comunidade científica em geral. Entende-se, então, que a construção do significado de meio ambiente ocorre fora da cientificidade devido ao seu caráter difuso e variado, moldando-se assim como uma representação social ${ }^{12}$. Essa perspectiva reforça o caráter preocupante da percepçáo de meio ambiente construída pelos profissionais participantes dos estudos anteriormente citados, pois a representação construída por eles vai de encontro à interação almejada em tempos de crise.

Contrária à percepção naturalística, algumas pesquisas apresentam concepçóes ampliadas de ambiente, onde enfermeiros, equipes de enfermagem e estudantes o caracterizam como sendo um espaço de interação mútua, onde o social e o ambiental relacionam-se com interdependência, sendo o espaço das relaçóes humanas (A2, A4, A12). Tais relaçôes podem ainda ser entendidas como benéficas ou maléficas ao ambiente e à saúde. Essa percepção é observada em estudos com estudantes do ensino fundamental, quando se utilizam da vivência local para descrever a relação do homem com o ambiente, caracterizando a relação homem-ambiente como predatória, balizada por interesses econômicos que afetam negativamente a sustentabilidade do meio (A8, A11).

A percepção de ambiente a partir da vivência, como apontado pelos estudantes, nada mais é do que a representação do percebido, onde cada pessoa o delimita em função de seus conhecimentos específicos e experiências cotidianas num determinado tempo e espaço. Alia-se a isso, na conceitualização de ambiente, a característica de esse ser composto por relaçóes dinâmicas e interativas, o que indica uma constante mutação a partir da dialética das relaçôes entre os grupos sociais, o meio natural e o construído. Assim, esse emaranhado de características implica em um processo de criação permanente, que estabelece e caracteriza culturas em tempo e espaços específicos $^{12}$.

Frente às percepções de ambiente vinculadas à degradação ambiental, alguns estudos abordam o que pensam enfermeiros e estudantes sobre a atual problemática ambiental, revelando, assim, a ideia de que a sociedade está se deparando com um grave e difícil problema devido, principalmente, à falta de sensibilidade das pessoas e ao avanço tecnológico desmedido (A2, A4). Entretanto, os autores destacam que muitos dos sujeitos alegam desenvolver açóes de preservação ambiental em seus domicílios, mas que essa ainda não parece ser uma ação bastante concreta, o que coloca em xeque a crítica sobre a falta de sensibilidade das pessoas (A3).

Combater a desordem ambiental é imprescindível para o viver saudável e em harmonia com a natureza, sendo que, para isso, necessita-se do surgimento de uma nova ética dos comportamentos humanos, pautada na vida democrática e nos valores culturais ambientalmente responsáveis. Nessa vertente, as práticas de preservação ambiental devem estar presentes na vida das pessoas, seja no trabalho ou domicílio, dando início a uma nova postura na forma de ver a relaçáo homem-ambiente. ${ }^{13}$

A percepção sobre a relação entre ambiente e saúde, ou saúde ambiental, evidenciada nos estudos, aponta para reflexos de uma formação prioritariamente biomédica, centrada na linearidade doença-cura, enfatizando a necessidade do controle de epidemias, doenças nutricionais, infecciosas, crônicas e degenerativas, assim como o acometimento do aspecto psicológico, por meio da depressão e outros distúrbios do comportamento devido à deterioraçáo do ambiente social (A2, A7, A10). Em outra corrente de pensamento, alguns estudos relatam a relação intrínseca da saúde ambiental com a promoção da saúde humana, vislumbrando o cuidado individual e coletivo como base para o cuidado do planeta e estabelecendo conexóes com o uso indevido de agrotóxicos, corrida pelo mercado armamentista e o lucro exacerbado incentivado pelo panorama capitalista global (A7, A10).

Os resultados encontrados, ora apresentando percepçóes norteadas por um viés biomédico, ora pautadas em uma corrente de promoção da saúde, nada mais são do que o reflexo da história da construção da concepção de saúde pela comunidade científica nas últimas décadas. A concepção de saúde como multifatorial, abordando aspectos socioambientais, tornou-se mais evidente a partir dos anos 1970, onde até então preponderou a 
atenção para os aspectos biológicos centrados na doença de indivíduos e populaçóes ${ }^{14}$. Dessa forma, as diferentes correntes de pensamento sobre a relação saúde-ambiente, podem ser entendidas, também, como o resultado da formação desses profissionais que, ou pelo período de formação ou concepção da escola formadora, estruturam suas percepçóes baseando-as de acordo com esses fatores.

Embora as pesquisas apresentem as diferentes percepçóes de ambiente, da problemática ambiental e da relação entre saúde e ambiente, a partir da voz dos sujeitos investigados, elas também apontam para uma preocupação em comum: o necessário cuidado com o atual cenário ambiental do globo. Esta constatação encontra-se destacada pelos estudos quando abordam sobre a necessidade do cuidado coletivo do planeta em todas as esferas socioambientais, das questóes mais naturalizadas (queimadas, água, contaminação do solo etc.) até aquelas com viés majoritariamente social (educação, economia, segurança etc.), partindo do ambiente local para interferir no ambiente global (A8, A11). Destaca-se, assim, a constatação levantada, onde o respeito para com o outro, com o coletivo e a responsabilidade social são deveres de todos, a priori, de cada individuo, que, consequentemente, beneficiarão o coletivo, ainda que alguns não percebam as influências múltiplas, imprevisíveis e a repercussão de suas açôes ${ }^{2}$.

\section{Resíduos dos serviços de saúde e seu gerenciamento}

A correta gestão dos Resíduos dos Serviços de Saúde (RSS) caracteriza-se como um dos grandes desafios a serem enfrentados dentro da problemática ambiental mundial. ${ }^{15}$ Essa preocupação encontra-se refletida nos estudos sobre enfermagem e meio ambiente selecionados nessa revisão, de maneira que $42,8 \%$ das pesquisas $(n=6)$ tecem consideraçóes ou investigam questóes referentes ao gerenciamento de resíduos, revelando um cenário preocupante quanto ao conhecimento e sensibilidade dos profissionais de saúde, e consequentemente de enfermagem, sobre a temática.

Embora seja consenso nos diferentes estudos que a produção de resíduos está atrelada aos procedimentos da equipe de enfermagem nas diferentes situaçôes de assistência, também é explícito que os trabalhadores da equipe desconhecem como se dá o processo de gerenciamento desses resíduos (A1, A2, A3). Essa constatação pode ser interpretada como um distanciamento entre o trabalho hospitalar e a questão ecológica, revelando que, além da precariedade no conhecimento dos trabalhadores sobre normas e diretrizes que regem a gestáo de resíduos, há uma falta de sensibilidade frente aos problemas ambientais que assolam diferentes comunidades e a própria saúde do trabalhador ${ }^{16}$.

Estes resultados vão ao encontro dos dados de outra pesquisa, ao corroborar com a perspectiva de que existem dificuldades para o gerenciamento dos RSS, fazendo-se a ressalva de que isso ocorre tanto no serviço de alta complexidade tecnológica quanto nos serviços de Atenção Básica ${ }^{17}$.

As pesquisas retratam também que, ainda que alguns trabalhadores detenham certo conhecimento sobre a gestão de resíduos, esses comumente restringem sua percepção e atuação à segregação do material contaminado daquele não contaminado dos serviços, esquecendo-se da importância que o material reciclável desempenha na sustentabilidade do meio e nas finanças da instituição (A1, A3). Outro estudo revelou que alguns profissionais demonstram preocupação quanto à adequação do armazenamento e da embalagem dos recipientes que recebem os resíduos, mas poucos traçam reflexões sobre os aspectos ambientais dessas atitudes, tampouco sobre o volume de resíduos gerado e o seu real destino final (A13)

O processo de gerenciamento dos resíduos é percebido ainda como atividade complexa, difícil e que causa conflitos entre os trabalhadores da saúde, tendo em vista a dificuldade encontrada por enfermeiros em sensibilizar a equipe atuante em seu setor sobre a correta segregação dos resíduos (A3). Contudo, sabe-se que diante da complexidade e dos avanços tecnológicos nos processos de cuidar, a enfermagem necessita aliar-se à sustentabilidade ambiental, repensando sua prática e formulando estratégias e procedimentos capazes de minimizar a capacidade produtiva do contexto hospitalar com açóes na separação, reciclagem e destino final do lixo ${ }^{15}$.

As dificuldades encontradas, principalmente por enfermeiros, na gestão dos resíduos, acarretam em uma relação de distanciamento do processo de gerenciamento no espaço de trabalho. Essa constatação é reforçada nos diferentes estudos que investigaram instituiçóes hospitalares, revelando ainda desconformidades dos sujeitos com a atitude de profissionais de outras categorias. Nesse cenário, os próprios enfermeiros participantes dos estudos enfatizam a necessidade do trabalho conjunto com outros profissionais de saúde, de maneira que todos devem integrar o somatório de trabalhadores imbuídos de responsabilidade para a conservação do ambiente (A1, A3, A13).

Tal perspectiva, do desinteresse dos profissionais da saúde pelo gerenciamento dos resíduos também pode ser reflexo do desconhecimento ou falta de incentivo, embora se saiba que o correto gerenciamento dos RSS precisa ser compreendido por todos os trabalhadores, não como uma tarefa menos importante, mas como etapa fundamental do trabalho produzido em equipe ${ }^{17}$. 
Um dado relevante observado em um dos estudos realizado com enfermeiros aborda que quando questionados sobre sua responsabilidade ambiental e frente aos resíduos, alguns sujeitos terceirizam seu compromisso no momento em que atribuem ao Serviço de Higiene e Limpeza da instituição a competência de realizar a gestâo adequada dos resíduos (A3). Tal percepção faz emergir a necessidade de uma reflexáo ética por parte dos profissionais, no intuito da enfermagem tomar o desafio de pensar soluçóes para o gerenciamento dos RSS como inerente ao cuidado, construindo o conhecimento necessário para decidir sobre essa questão ${ }^{15}$.

O desconhecimento, a falta de apoio e a não sensibilidade com relação aos RSS e com a temática ambiental se propagam ao ambiente domiciliar de alguns participantes das pesquisas, de maneira que o desenvolvimento de açôes de preservação ambiental náo se mostra uma ampla realidade por esses participantes. Evidencia-se ainda que aqueles que realizam alguma ação de cunho ambiental normalmente restringem-se à segregação do material reciclável. Já outros sujeitos criticam a participação do poder governamental com relação ao apoio, estrutura e organização das cidades para a efetivação da coleta seletiva, o que acaba desestimulando ações ambientalmente responsáveis (A2, A13).

A participação das instituiçôes de saúde em cursos, capacitaçōes ou programas de educação também parece ser ainda incipiente, principalmente no que diz respeito a abordagens com viés socioambiental, pois se restringem, por vezes, a questóes instrumentais de segregação, quando realizam alguma iniciativa (A1). A situação descrita demonstra a necessidade de se investir em abordagens que aprofundem a discussão acerca dessa temática, constatação já levantada por enfermeiros hospitalares quando demonstram ter clareza de que é necessário colaborar com o processo de conscientizaçáo por meio do desenvolvimento da educação em serviço (A3).

Dessa forma, visualiza-se que apesar das pesquisas apontarem a pouca instrumentalização das equipes de saúde sobre o tema, infere-se também que houve avanços ao longo dos anos no que se refere à atuaçáo da equipe perante a segregação dos $\mathrm{RSS}^{18}$. Nesse processo, destacam-se os profissionais de enfermagem como protagonistas das questóes processuais dos RSS e da preocupação com a problemática ambiental, reforçando um desejo de mudança através da reflexão e análise crítica consciente de sua realidade ${ }^{15}$.

O profissional enfermeiro deve desempenhar, neste cenário de crise, seu papel de educador, praticando, orientando e capacitando sua equipe e demais pessoas para a ampliação do debate acerca da temática. Assim, por meio de uma educação ambiental, estará trabalhando também na reorientação dos conhecimentos mecanizados do cuidado para uma atenção ao ser em sua totalidade através da prática do cuidado holístico. Esse processo de educaçáo pauta-se no entendimento de que para a transformaçáo de uma cultura, necessita-se, em primeira instância, da conversão e mudança pessoal/ particular, resultando, assim, em uma nova forma de comportamento relacional ${ }^{1-16}$.

Faz-se necessário, então, estimular o valor de responsabilidade com o ambiente como inerente ao profissional de saúde, entendendo a sensibilidade para as questôes ambientais como uma decisão particular, mas que deve ser estimulada e ganha força na estrutura coletiva. ${ }^{16-19}$ Dessa forma, depreende-se que os profissionais das diferentes esferas de atenção à saúde estejam imbuídos dessa atribuiçấo de responsabilidade, uma vez que, os problemas ecológicos atingem todas as pessoas ${ }^{16}$.

\section{Formação profissional em enfermagem: ampliando possibilidades}

Fomentar o debate sobre a relação saúde e meio ambiente, por meio de uma visão integradora, na formação profissional em saúde, e consequentemente na enfermagem, apresenta-se como a principal estratégia de ação entre os estudos, estando essa percepçáo presente em 64\% deles ( $\mathrm{n}=9)$ (A1, A2, A4, A5, A6, A7, A8, A10). Uma das publicaçóes reitera, inclusive, a necessidade da discussão por meio da educação continuada para enfermeiras assistenciais (A14).

Inserir uma discussão orientada pela perspectiva socioambiental, percebendo o cuidado ao ser humano em conjunto com o ambiente, pode ser a solução frente ao que alguns enfermeiros e estudantes da área da saúde relataram nas pesquisas, quando se referem à situação de existência de uma abordagem superficial das questốes ambientais na formaçấo (A2, A4). Tal constatação é corroborada pelo estudo com acadêmicos quando sinalizam não se verificar um processo reflexivo mais aprofundado do assunto, embora se sintam afetados, de alguma maneira, pela problemática ambiental contemporânea (A4).

A superficialidade das representações sociais de acadêmicos de enfermagem sobre o conceito de meio ambiente também é percebido em outra pesquisa, demonstrando a fragilidade da inserção da temática na formação desses profissionais ${ }^{20}$. Dessa forma, os estudos reafirmam a eminência de se pensar em estratégias pedagógicas na enfermagem que potencializem e aprofundem o debate sobre a temática ambiental no processo de formação, construindo conhecimentos sólidos para a ação dos profissionais nas diferentes instâncias de atuação (A2, A8), conhecimentos que permitam ao enfermeiro, por exemplo, exercer um de seus papéis fundamentais na sociedade, assim como uma das bases que sustenta a profissão, que é a sua essência educadora ${ }^{19}$. 
A enfermagem, através de açóes de promoção da saúde, pode inserir-se no campo de conhecimentos socioambientais e trabalhá-lo na educação de indivíduos e comunidades, instigando a reflexão, a mudança de comportamentos e despertando um sentimento de solidariedade ao considerar o ambiente um fator relacionado à vida (A6, A10).

Neste ínterim, alguns estudos demonstram a participação do enfermeiro na escola, ambiente propício para o despertar de uma nova ética, reafirmando também o papel da própria escola como instrumento no desenvolvimento e no fortalecimento de uma consciência ambiental do estudante, caracterizando-se uma açáo conjunta entre escola, instituição de saúde, educador e sociedade (A11). Tal iniciativa reforça a imprescindível participaçáo comunitária, que atenta, interessada e responsável, se torna aliada no enfrentamento dos problemas ambientais (A5).

Outra forma de inserção da enfermagem no âmbito das questóes ambientais, que pode ser utilizado como exemplo na formação profissional, está relacionada à vigilância sanitária, na qual alguns enfermeiros entrevistados consideram a atuação na área ambiental como essência da profissão. Em oposiçáo, outros depoentes referiram ser essa uma nova área de atuação, mas que amplia assim o escopo da profissão (A13). Alguns departamentos de saúde dos Estados Unidos da América estão ao encontro dessa perspectiva, país onde já há um plano estratégico nacional para ampliar o papel dos enfermeiros como participantes ativos na prática de saúde ambiental, demonstrando o despertar da profissão para um novo olhar sobre o cuidado na saúde (A14).

Principalmente no Brasil, por meio do Sistema Único de Saúde, deve-se destacar com intensidade a participaçáo de enfermeiros nos debates sobre as questóes ambientais e de saúde, tendo em vista que esses profissionais são protagonistas de políticas públicas de saúde, trabalhando a universalidade, equidade e integralidade como eixo condutor de sua prática. ${ }^{15}$ Essa realidade assinala o quão importante é o debate sobre a relação saúde e ambiente desde o início da formação profissional, perpassando, de modo transversal, as diferentes disciplinas e sensibilizando a perspectiva de cuidado para dimensões múltiplas, interativas, integrativas e inter-relacionais da relação homem/ambiente ${ }^{2}$.

Sabe-se ainda que embora seja imprescindível a incorporação das questóes ambientais no ensino superior, essas questóes são uma problemática social, que transcende a incumbência unicamente das universidades, devendo ser trabalhada em todos os níveis de formação, assim como na reciclagem de profissionais ${ }^{13}$.

Para que este leque de possibilidades de atuação do enfermeiro se concretize em uma prática ambientalmente sensível e responsável, faz-se imprescindível que o cuidado com o ecossistema também seja visto como um cuidado de enfermagem, pautado em uma atitude ética perante demandas ambientais, fortalecendo esse novo paradigma de cuidado ${ }^{1,2-19}$. Acrescenta-se ainda, nessa vertente da construçáo de novos conhecimentos, um chamamento com relação às pesquisas sobre o tema, que embora venham se modificando de um cenário voltado para reflexóes teórico-filosóficas e éticas (A9) em direção a investigaçóes de campo, a temática ainda carece de pesquisas intervencionistas onde o enfermeiro exercite seu potencial criativo, aliando, talvez, sua postura ambientalmente ética a novas tecnologias em prol do cuidado socioambiental.

\section{Considerações Finais}

O atual cenário de crise ambiental tem levado a comunidade científica a debater sobre suas concepçóes e práticas. Por ser profissão originalmente cuidadora, a enfermagem precisa incluir-se nessa discussão de forma particular, no intuito de se buscarem subsídios para o desenvolvimento de uma consciência ambiental entre os trabalhadores da área. Nessa perspectiva, as produções científicas sobre a relação enfermagem e ambiente apontam para um cenário preocupante quanto às concepçôes de ambiente de alguns profissionais e estudantes, que ainda o percebem de forma naturalística. Entretanto, também se fazem presentes algumas concepçōes integradoras, que visualizam uma inter-relação entre sociedade e ambiente. Acrescenta-se também à dicotomia presente, não excludente, a percepção de saúde ambiental por dois olhares: o biomédico e o da promoção da saúde.

Os estudos reiteram a emergência do cuidado com o ambiente, dando ênfase à problemática dos resíduos dos serviços da saúde, principalmente no que tange seu gerenciamento. Sobre isso, percebe-se certo desconhecimento perante o gerenciamento dos resíduos, demonstrando-se também uma atividade complexa e que exige atenção multiprofissional, mas que muitas vezes é deixada de lado e delegada a outros serviços, como o de higiene e limpeza. Nesse cenário, as pesquisas reforçam a importância do enfermeiro em assumir o papel de educador na equipe de saúde, resgatando a sensibilidade e as responsabilidades dos outros profissionais para com a temática.

A preocupação com a formação profissional do enfermeiro também foi pauta de discussōes nos artigos selecionados. Nessa perspectiva, relatam-se fragilidades apontadas nas pesquisas pelos sujeitos na abordagem da temática ambiental na formação dos profissionais. Diante disso, são apresentadas possibilidades de atuação 
do enfermeiro com base no cuidado ambiental, assim como a ideia de inclusão da abordagem socioambiental na formação desse profissional.

Considera-se então fundamental a realização de novas pesquisas, que fortifiquem o conhecimento da enfermagem na temática socioambiental, revelando também novas concepçóes e práticas presentes no trabalho do enfermeiro. Faz-se ressalva quanto à singela participação de estudos intervencionistas, assim como a carência de pesquisas que trabalhem diretamente com o processo de formação profissional na temática. Reitera-se assim a importância do tema para a busca de uma realidade ambientalmente responsável e, consequentemente, mais saudável.

\section{Referências}

1. Monteiro EMLM, Rolim KMC, Machado MFAS, Moreira RVO. A visão ecológica: uma teia na enfermagem. Rev Bras Enferm. 2005;58(3):341-4.

2. Baggio MA, Callegaro GD, Erdmann AL. Significando o cuidado ecológico/planetário/coletivo/do ambiente à luz do pensamento complexo. remE - Rev. Min. Enferm. 2011 jan-mar;15(1):11-18.

3. Beserra EP, Alves MDS, Rigotto MR. Percepção de adolescentes acerca da saúde ambiental: pesquisa-ação no espaço escolar. Online braz j nurs. 2010;9(1).

4. Camponogara S, Kirchhof ALC, Ramos FRG. A relação enfermagem e ecologia: abordagens e perspectivas. R Enferm UERJ. 2006 jul-set;14(3):398-404.

5. J Wakefield. Environmental florence nightingales: nursing's new front line. Environ Health Perspect. 2001 mar;109(3):A118-A123.

6. Ribeiro MCS, Bertolozzi MR. A questáo ambiental como objeto de atuação da vigilância sanitária: uma análise da inserção das enfermeiras nesse campo. Rev Latino-Am Enferm. 2004 set-out;12(5):736-44.

7. Rother ET. Revisão sistemática x revisão narrativa. Editorial. Acta Paulista Enferm. 2007;20(2).
8. Cordeiro AM, Oliveira GM, Renteria JM, Guimarães CA. Revisão sistemática: uma revisão narrativa. Rev Col Bras Cir. 2007 nov-dez;34(6):428-431.

9. Minayo MCS. O desafio do conhecimento: pesquisa qualitativa em saúde. São Paulo: Hucitec; 2010.

10. Coordenação de Aperfeiçoamento de Pessoal de Nível Superior. Diretoria de Avaliação. Documento de área da enfermagem; 2013.

11. Turato ER. Métodos qualitativos e quantitativos na área da saúde: definiçôes, diferenças e seus objetos de pesquisa. Rev Saúde Pública. 2005;39(3):507-14.

12. Reigota M. Meio ambiente e representação social. São Paulo: Cortez; 2010.

13. Leff E. Saber ambiental: sustentabilidade, racionalidade, complexidade e poder. Petrópolis: Vozes; 2011.

14. Heidemann ITSB, Boehs AE, Fernandes GCM, Wosny AM, Marchi JG. Promoção da saúde e qualidade de vida: concepçôes da carta de ottawa em produção científica. Cienc Cuid Saude. 2012 jul/set;11(3):613-619.

15. Silva ITS, Bonfada D. Resíduos sólidos de serviços de saúde e meio ambiente: percepção da equipe de enfermagem. Rev Rene. 2012;13(3):650-7.

16. Soares SGA, Camponogara S, Terra MG, Santos TM, Trevisan CM. O que pensam os enfermeiros sobre a problemática ambiental. Rev Rene. 2012;13(5):971-82.

17. Gessner R, Piosiadlo LCM, Fonseca RMGS, Larocca LM. O manejo dos resíduos dos serviços de saúde: um problema a ser enfrentado. Cogitare Enferm. 2013 jan/ mar;18(1):117-23.

18. Camponogara S, Soares SGA, Terra MG, Santos TM, Trevisan CM. Nurses involved in management of hospital residues: a descriptive study. Online braz j nurs. 2012 aug;11(2):289-304.

19. Beserra EP, Alves MDS, Pinheiro PNC, Vieira NFC. Educação ambiental e enfermagem: uma integração necessária. Rev Bras Enferm. 2010 set-out;63(5):848-52.

20. Bruzos GAS, Kamimura HM, Rocha SA, Jorgetto TAC, Patrício KP. Meio ambiente e enfermagem: suas interfaces e inserção no ensino de graduação. Saúde Soc. 2011;20(2):462-469. 